Orijinal araştırma-Original research

\title{
Plazminojen aktivatör inhibitör-1 (PAI-1) 4G/4G polimorfizminin gebelik kayıplarıyla ilişkisi
}

\author{
The association of plasminogen activator inhibitor-1 (PAI-1) 4G/4G \\ polymorphism with miscarriages
}

\section{Malik Ejder Yıldırım*, Şeker Dağ, Hande Küçük Kurtulgan, Savaş Karakuş}

Tıbbi Genetik Anabilim Dalı (Dr. M. E. Yıldırım, Yrd. Doç. Dr. H. K. Kurtulgan), Kadın Hastalıkları ve Doğum Anabilim Dalı (Yrd. Doç. Dr. S. Karakuş), Cumhuriyet Üniversitesi Tıp Fakültesi, Biyoloji Bölümü (Yrd. Doç. Dr. Ş. Dağ), Cumhuriyet Üniversitesi Fen Fakültesi, TR58140 Sivas

\section{Özet}

Amaç. Plazminojen aktivatör İnhibitörü Tip 1 (PAI-1) bir serin proteaz inhibitörüdür. Doku plazminojen aktivatörü (tPA) ve ürokinazı (uPA), sonuç olarak fibrinolizi inhibe eder. Genin promotor bölgesinde $4 \mathrm{G} / 5 \mathrm{G}$ olarak bilinen bir polimorfizm söz konusudur. Trombozdaki rolü nedeniyle PAI-1 4G/4G polimorfizminin gebelik komplikasyonlarına katkısı olabileceği düşünülmektedir. Biz bu çalışmada, PAI-1 $4 \mathrm{G} / 4 \mathrm{G}$ polimorfizminin gebelik kayıplarına olası etkisini değerlendirmeyi amaçladık. Yöntem. Çalışma grubu Sivas bölgesinde yaşayan bireylerden seçildi. Araştırmaya 92'si bir veya daha fazla düşük öyküsü olan ve 86 kontrol olmak üzere toplam 178 kadın dahil edildi. Gen mutasyonlarını belirlemek için periferik kan örneklerinden DNA izolasyonu ve sonrasında revers hibridizasyon ilkesine dayanan strip assay tekniği ile mutasyon analizi yapıldı. Veriler SPSS 15,0 istatistik programı aracılığıyla değerlendirildi. Bulgular. Kontrol grubunda $5 \mathrm{G} / 5 \mathrm{G}$ polimorfizmi $22(\% 25,6)$, $4 \mathrm{G} / 5 \mathrm{G}$ polimorfizmi $53(\% 61,6)$ ve $4 \mathrm{G} / 4 \mathrm{G}$ mutant olgular $11(\% 12,8)$ olarak tespit edilmiştir. Düşük olgularında ise $5 \mathrm{G} / 5 \mathrm{G}$ polimorfizmi 20 $(\% 21,7), 4 \mathrm{G} / 5 \mathrm{G}$ polimorfizmi $49(53,3)$ ve $4 \mathrm{G} / 4 \mathrm{G}$ mutant olgular ise $23(\% 25)$ bulunmuştur. $4 \mathrm{G} / 4 \mathrm{G}$ homozigot mutant olgular için ODDS değeri hesaplanmıştır. Sonuç. Bulgularımıza göre $5 \mathrm{G} / 5 \mathrm{G}$ ve $4 \mathrm{G} / 5 \mathrm{G}$ polimorfizmleri düşük açısından risk artışı sağlamamaktadır ( $\mathrm{p}=0,546$ ve $\mathrm{p}=0,259 \mathrm{p}>0,05)$. Çalışmamızda PAI-1 4G/4G polimorfizminin düşük riskine katkısı anlamlı bulunmuştur. Bu polimorfizme sahip kadınlarda düşük yapma riski 2,27 kat daha fazladır ( $\mathrm{p}=0,038$ $\mathrm{p}<0,05)$.

Anahtar sözcükler: PAI-1, 4G/4G polimorfizmi, düşük

\begin{abstract}
Aim. Plasminogen activator inhibitor type 1 (PAI-1) is a serine protease inhibitor. It inhibits tissue plasminogen activator (tPA) and urokinase (uPA), and consequently inhibits fibrinolysis. There is a common polymorphism known as $4 \mathrm{G} / 5 \mathrm{G}$ in the promoter region of PAI-1 gene. PAI-1 $4 \mathrm{G} / 4 \mathrm{G}$ polymorphism may contribute pregnancy complications because of its role in thrombosis,. In this study, we aimed to evaluate the possible effect of PAI-1 4G/4G polymorphism to miscarriages. Method. The study group was selected between individuals residing in Sivas region. One hundred and seventy eight women ( 92 of them have miscarriage story and 86 control) were incorporated to study. After DNA isolation, mutation analysis was performed by StripAssay technique based on the reverse-hybridization principle. Data were analysed by SPSS 15.0 statistic program. Results. In control group, the number of $5 \mathrm{G} / 5 \mathrm{G}$ polymorphisms was $22(25.6 \%)$, the number of $4 \mathrm{G} / 5 \mathrm{G}$ polymorphisms was $53(61.6 \%)$ and the number of $4 \mathrm{G} / 4 \mathrm{G}$ mutant cases was $11(12.8 \%)$. In miscarriage group, the number of $5 \mathrm{G} / 5 \mathrm{G}$ polymorphisms was $20(21.7 \%)$, the number of $4 \mathrm{G} / 5 \mathrm{G}$ polymorphisms was $49(53.3 \%)$ and the number of 4G/4G mutant cases was $23(25 \%)$. ODDS ratio was calculated for $4 \mathrm{G} / 4 \mathrm{G}$ homozygot mutant cases. Conclusion. According to our datas, $5 \mathrm{G} / 5 \mathrm{G}$ and $4 \mathrm{G} / 5 \mathrm{G}$ polymorphism have not higher risk for miscarriage $(\mathrm{p}=0.546$ and $\mathrm{p}=0.259$ $\mathrm{p}>0.05$ ). In our study, it was detected that the contribution of $4 \mathrm{G} / 4 \mathrm{G}$ polymorphism to miscarriage is important. The women who have this polymorphism carry the risk of miscarriage higher 2.27 fold $(\mathrm{p}=0.038 \mathrm{p}<0.05)$.
\end{abstract}

Keywords: PAI-1, 4G/4G polymorphism, miscarriage 
Geliş tarihi/Received: 07 Ağustos 2014; Kabul tarihi/Accepted: 20 Eylül 2014

*İletişim adresi:

Dr. Malik Ejder Yıldırım, Tıbbi Genetik Anabilim Dalı, Cumhuriyet Üniversitesi Tıp Fakültesi, TR-58140 Sivas. E-posta: mey2002@gmail.com

\section{Giriş}

İnsan Plazminojen Aktivatörü İnhibitörü Tip 1 (PAI-1) doku plazminojen aktivatörü (tPA) ve ürokinaz (UPA) adı verilen proteazları inhibe eden bir serin proteaz inhibitörüdür [1]. Fibrinoliz mekanizmasında denge unsurlarından birisidir. Ana fonksiyonu fibrinolitik aktiviteyi azaltmak ve bu yolla fibrin birikimi sağlamaktır [2]. Serpin-1 olarak da adlandırılır. Plazminojen aktivatör inhibitörü Tip 1 proteaz inhibitörlerinin serpin ailesine ait 379 aminoasitlik ve 45-kDa'luk bir glikoprotein yapıdır [3]. PAI-1 geni 7. kromozomda lokalizedir (7q21,3-q22). PAI-1'in aterotromboz oluşumunda önemli bir rol oynayabileceğini ileri süren çalışmalar olup koroner kalp hastalarında dolaşımdaki PAI-1 düzeyi yüksek bulunmuştur [4]. PAI-1 4G aleli 5G'ye oranla transkripsiyonel olarak daha aktiftir. PAI-1 4G/5G polimorfizminin iskemik stroke (İnme) olaylarıyla bağlantısı olduğuna dair deliller mevcuttur [5]. Değişik çalışmalarda elde edilen veriler PAI-1 polimorfizminde $4 \mathrm{G} / 4 \mathrm{G}$ varyantının kalıtımsal bir koroner risk faktörü olduğunu ve dolayısıyla koroner kalp hastalığı ve miyokardial iskemiye katkısı olabileceğini desteklemektedir [6, 7]. Yüksek PAI-1 aktivitesi ve 4G varyantının miyokard infarktüsü riskini artırdığ düşünülebilir [8]. PAI-1 değişik kanserlerde kanser hücrelerinin bazal laminaya invazyonunda önemli rol oynayan metalloproteinaz aktivitesini etkilemekte, perivazküler boşluktan tümör dokusuna endotelyal hücre migrasyonunu artırarak anjiogenez için anahtar görevi üstlenmektedir. Bu özellik PAI-1'in kanser progresyonuna katkısını açıklamaktadır [9]. PAI-1 aktivitesinin trombozla bağlantısı olması nedeniyle gebelikte anne dolaşımını, dolayısıyla plasental dolaşımı da etkileyebileceğini düşünebiliriz. $\mathrm{Bu}$ bağlamda, PAI-1 aktivitesinin daha yüksek olduğu 4G/4G polimorfizminin gebelik kayıplarıla ilişkisi olabileceği akla gelmektedir. Bu çalışmada biz düşük öyküsü olan kadınları kontrol grubu ile karşılaştırıp PAI-1 4G/5G polimorfizminin düşük olgularına katkısını değerlendirdik.

\section{Gereç ve yöntem}

Araştırmaya Aralık 2010 ve Aralık 2011 yılları arasında Sivas Devlet Hastanesi'nde bir veya daha fazla düşük öyküsü bulunan 92 hasta ve 86 kontrol olmak üzere toplam 178 kadın dahil edildi. Çalışmamız retrospektif nitelik taşımaktadır. Her iki gruptaki bireyler 22-41 yaşlar arasındaydı (Düşük öyküsü olan grupta ortalama yaş 28, kontrol grubunda 30). Bireylerden 2cc periferik venöz kan alınarak EDTA'lı tüpe aktarıld1, tüpler etiketlenerek kullanılıncaya kadar $-20{ }^{\circ} \mathrm{C}$ 'de muhafaza edildi. Kontrol grubundaki bireylerde çeşitli hastalıklarla ilgili öyküleri (kardiyovazküler ve serebrovazküler hastalıklar, kanser, düşük veya tekrarlayan düşük) sorgulandı ve olmadığı teyit edildi. Çalışmaya alınan düşük olgularında gebelik kaybı ile ilişkili olabilecek diğer parametreler (tiroit hastalıkları, diğer endokrin bozukluklar, jinekolojik anomaliler, hipertansiyon, sistemik hastalıklar, sigara ve alkol öyküsü, polikistik over sendromu) taranmış ve bu olgular ekarte edilmiştir. Bireylerin genomik DNA izolasyonu periferik kandan yapıldı. Bunun için Invitek Invisorb Spin Blood DNA İzolasyon Kiti kullanıldı. PAI-1 geninin ilgili bölgelerinin çoklu (multipleks) amplifikasyonu için Vienna Lab CVD PCR amplifikasyon kiti kullanıldı. Hibridizasyon işleminden önce elde edilen PCR ürünleri (4 $\mu \mathrm{L}) \% 1$ 'lik elektroforezde başarılı amplifikasyonlar açısından değerlendirildi. Başarılı amplifikasyon elde edilen PCR ürünlerinden $10 \mu \mathrm{L}$ ürün revers hibridizasyon yöntemiyle analiz için kullanıldı. Southern Blot analiz için Revers-Hibridizasyon ProfiBlot T48 (Tecan) Hibridizasyon cihazı kullanıldı. Stripler oda sıcaklığında $1 \mathrm{ml}$ konjugat solüsyonu ile 15 dak. inkübe edilerek konjugat solüsyonu içinde bulunan streptavidin-alkalan fosfataz, biyotin işaretli hibrit DNA fragmentlerine bağlanması sağlandı. Strip üzerindeki 
hibridize olmuş bantların görülür hale gelebilmesi için ortama $1 \mathrm{ml}$ alkalan fosfatazın subtrat1 olan nitro blue tetrazolium (NBT) ve 5-bromo-4-kloro-3-indolil fosfatdan (BCIP) oluşan renk geliştiricisi (color developer) eklendi, oda sıcaklığında 15 dak. inkübasyona tabi tutuldu. Strip son olarak distile su ile yıkandı, kâğıt havlu ile kurutulduktan sonra değerlendirme tablosuna (Collector) yerleştirildi. Strip düzeneğinde $4 \mathrm{G}$ ve $5 \mathrm{G}$ bantları sayıldı ve alelik kombinasyonlar değerlendirildi (4G/4G homozigot, 5G/5G homozigot, 4G/5G Heterozigot). Çalışma sonucu elde edilen verilerin istatiksel olarak değerlendirilmesinde SPSS programı kullanılıp, verilerin değerlendirilmesinde ki-kare testi uygulanmış, ODDS değeri ve \%95 güven aralıkları hesaplanmış, yanılma düzeyi 0,05 olarak alınmıştır.

\section{Bulgular}

Çalışma sonucunda kontrol grubundaki 86 bireyden 22 'sinde $(\% 25,6) 5 \mathrm{G} / 5 \mathrm{G}, 53$ 'ünde $(61,6) 4 \mathrm{G} / 5 \mathrm{G}$ ve 11 'inde $(\% 12,8) 4 \mathrm{G} / 4 \mathrm{G}$ polimorfizmi tespit edildi. Bir veya daha fazla düşük öyküsü olan hasta grubunda ise 92 hastadan 20'sinde $(\% 21,7) 5 \mathrm{G} / 5 \mathrm{G}, 49$ 'unda $(\% 53,3)$ 4G/5G, 23'ünde (\%25) 4G/4G polimorfizmi tespit edildi.

Düşük olguları ve kontrol grubu arasında $5 \mathrm{G} / 5 \mathrm{G}$ ve $4 \mathrm{G} / 5 \mathrm{G}$ alelik frekansı istatistiksel olarak anlamlı bir farklılık içermemektedir; 5G/5G polimorfizmi için ODDS değeri 0,80 olarak hesaplandı. (\%95 güven aralığ1). Bu olgularda düşükler açısından artmış bir risk bulunmamaktadır (Tablo 1).

Tablo 1. Gruplara ait PAI-1 5G/5G gen polimorfizminin karşılaştırılması.

\begin{tabular}{|c|c|c|c|c|}
\hline Gruplar & & 5G/5G Polimorfizmi & Diğer & Toplam \\
\hline Normal & $\mathrm{n}(\%)$ & $22(25,6)$ & $64(74,4)$ & $86(100)$ \\
\hline Hasta & $\mathrm{n}(\%)$ & $20(21,7)$ & $72(78,3)$ & $92(100)$ \\
\hline Total & $\mathrm{n}(\%)$ & $42(23,6)$ & $136(76,4)$ & $178(100)$ \\
\hline
\end{tabular}

4G/5G alelik frekansı için ODDS değeri 0,71 olarak hesaplandı. (\%95 güven aralığı). Bu olgularda düşükler açısından artmış bir risk bulunmamaktadır (Tablo 2).

Tablo 2. Gruplara ait PAI-1 4G/5G gen polimorfizminin karşılaştırılması.

\begin{tabular}{|c|c|c|c|c|}
\hline Gruplar & & 4G/5G Polimorfizmi & Diğer & Toplam \\
\hline Normal & $\mathrm{n}(\%)$ & $53(61,6)$ & $33(38,4)$ & $86(100)$ \\
\hline Hasta & $\mathrm{n}(\%)$ & $49(53,3)$ & $43(46,7)$ & $92(100)$ \\
\hline Total & $\mathrm{n}(\%)$ & $102(57,3)$ & $76(42,7)$ & $178(100)$ \\
\hline
\end{tabular}

4G/4G alelik polimorfizmi için ODDS değeri 2,27 olarak hesaplandı. (\%95 güven aralığı). Bu aralıkta 4G/4G homozigot mutant polimorfizmi düşükler açısından anlamlı bir risk faktörüdür. $\mathrm{Bu}$ gen polimorfizmine sahip dişi bireylerde düşük riski normal olgulara göre 2,27 kez daha fazladır (Tablo 3).

Tablo 3. Gruplara ait PAI-1 4G/4G gen polimorfizminin karşılaştırılması.

\begin{tabular}{lllll}
\hline Gruplar & & 4G/4G Polimorfizmi & Diğer & Toplam \\
\hline Normal & $\mathrm{n}(\%)$ & $11(12,8)$ & $75(87,2)$ & $86(100)$ \\
Hasta & $\mathrm{n}(\%)$ & $23(25)$ & $69(75)$ & $92(100)$ \\
Total & $\mathrm{n}(\%)$ & $34(19,1)$ & $144(80,9)$ & $178(100)$ \\
\hline $\mathbf{x}^{\mathbf{2}=\mathbf{4 , 2 8} ; \mathbf{p}=\mathbf{0 , 0 3 8} ; \mathbf{p}<\mathbf{0 , 0 5} \text { önemli }}$ & & \\
\hline
\end{tabular}

\section{Tartışma}

Gebelik döneminde kadınlarda fizyolojik değişiklikler söz konusu olmakta, sağlıklı gebeliklerde anne bu fizyolojik değişimlere adaptasyon sağlamaktadır. Ancak kadında gebeliğin seyrini etkileyebilecek kan dolaşımı ve pıhtılaşma ile ilgili kalıtsal özelliklerin olması da muhtemeldir. Anne ve fetus arasındaki ilişki plasenta aracılığıyla sağlanmakta ve bebeğin yaşamsal gereksinimleri anne dolaşımı aracılığıyla temin edilmektedir. 
Sağlıklı bir gebelik dönemi için dolaşımsal problemlerin olmaması gerekir. Pıhtılaşma bozuklukları yineleyen spontan düşüklerin nedenlerinden biridir [10]. Yapılan çalışmalar gebelik ve üreme fizyolojisi bakımından trombofilik genlerin önemini ortaya çıkarmıştır [11]. Bu bağlamda, gebe kadınların takibinde, özellikle düşük öyküsü olan kadınlar için trombofili paneli önem arzetmektedir. Herediter trombofililer ilk trimester'dan ziyade ikinci trimester düşükleriyle alakalı bulunmuştur [12]. Özellikle faktör V G1691A (Leiden), protrombin G20210A, faktör XIII V34L, beta-fibrinojen -455G>A, PAI-1 4G/5G, MTHFR C677T ve MTHFR A1298C polimorfizmlerindeki mutasyonlar pıhtılaşma mekanizmasını ve dolayısıyla feto-maternal dolaşımı etkilemekte ve düşüklere neden olabilmektedir. Çalışmaya dahil ettiğimiz 92 kadın olguda bir veya daha fazla düşük öyküsü vardı. Düşük öyküsü olmayan 86 kadın ise kontrol grubunu oluşturdular. Çalışmaya alınan her iki grup 22 ila 41 yaş arası kadınları içermektedir. Plazminojen aktivatör inhibitör Tip $14 \mathrm{G} / 5 \mathrm{G}$ polimorfizmi PAI-1 aktivitesi ile ilişkili bir polimorfizmdir ve $4 \mathrm{G}$ aleli $5 \mathrm{G}$ 'ye oranla daha aktiftir. Çalışmamızda düşük öyküsü olan kadınlarda 4G/4G mutasyonu kontrol grubuna oranla istatistiksel olarak anlamlı biçimde yüksek çıkmıştır (Tablo 3). 4G/4G mutasyonu olan bireylerin diğer alelik gruplara göre düşük yapma olasılığı 2,27 kez daha fazladır (ODDS değeri 2,27; \%95 güven aralığında). 2003 yılında Avusturya' da yapılan bir çalışma PAI-1 4G ve faktör XIII V34L homozigot olguların veya bu mutasyonların heterozigot birlikteliğinin erken gebelik kayıplarıyla ilişkili olduğunu desteklemektedir [13]. Bizim bulgularımız Avusturya çalışması ile uyumludur. Kimi çalışmalarda, yineleyen düşük olgularıyla kontrol grupları arasında PAI-1 polimorfizmi istatistiksel olarak anlamlı bir farklılık arz etmemekte, bulgular PAI1 4G/5G polimorfizmi ile yineleyen spontan düşüklerde risk artışını ilişkilendirememektedir [14, 15]. Trombofilik gen mutasyonlarının sıklığı konusunda düşük olguları ve kontrol grupları arasında istatistiksel olarak anlamlı farklılık bulunamayan çalışmalarda dahi homozigot mutasyonların düşük olgularında daha fazla olduğu tespit edilmiştir [16]. Reith ve arkadaşları PAI-1 ve PAI-2 üzerine yaptıkları bir çalışmada, preeklampsi olgularında PAI-1'in yükseldiğini ve muhtemelen plasental kitlede veya plasenta fonksiyonlarında azalmaya bağlı olarak PAI-2 düzeyinin belirgin olarak düştüğünü göstermişlerdir. Normal ve anormal gebeliklerin ayrımında PAI-1/PAI2 oranının kullanılmasının yararlı olacağını öne sürmektedirler [17]. Polikistik over sendromlu kadınlar üzerine çalışmalar yapan Glueck ve arkadaşları PAI aktivitesinin düşük olguları için bağımsız bir risk faktörü olduğunu ileri sürmüşlerdir [18]. Buchholz ve arkadaşları 4G alelinin homozigot olduğu olgularda bu riskin varlığını onaylamakta ve ACE D aleli ve PAI-1 4G aleli homozigot olan gebelerde tekrarlayan düşükleri önlemek için düşük moleküler ağırlıklı heparin tedavisi önermektedirler [19]. Öte yanda, Khosravi ve arkadaşları tekrarlayan düşük olgularında PAI-1 gen polimorfizmi açısından heterozigot değil ama homozigot olguların $(4 \mathrm{G} / 4 \mathrm{G})$ kontrol grubuna oranla belirgin olarak daha yüksek olduğunu tespit etmişlerdir [20]. PAI-1 geninin hipofibrinolitik 4G/4G polimorfizminin preeklampsi, abruptio plasenta, fötal gelişme geriliği ve ölü doğumlar için de önemli bir risk faktörü olabileceği ileri sürülmektedir [21]. Çalışmamızın sonuçları, PAI-1 4G alelinin homozigot olduğu kadınlarda bu mutasyonun diğer trombofili unsurlarından bağımsız olarak düşük olguları için bir risk faktörü olabileceğini düşündürmektedir. Bu bağlamda 4G homozigot gebe olgularında gebeliğin sağlıklı sürdürülebilmesi için profilaktik olarak antitrombotik tedavi planlanması önem kazanmaktadır. 


\section{Kaynaklar}

1. Mottonen J, Strand A, Symersky J, Sweet RM, Danley DE, Geoghegan KF, Gerard RD, Goldsmith EJ. Structural basis of latency in plasminogen activator inhibitor-1. Nature 1992: 355; 270-3.

2. Henry M, Chomiki N, Scarabin PY, Alessi MC, Peiretti F, Arveiler D FerrieresJ, Evans A, Amouyel P, Poirier O, Cambien F, Vague IJ. Five frequent polymorphisms of the PAI-1 gene lack of association between genotypes, PAI activity, and triglyceride levels in a healthy population. Arteriosclerosis, Thrombosis, and Vascular Biology 1997; 17: 851-8.

3. Magdoud K, Herbepin VG, Touraine R, Almawi WY, Mahjoub T. Plasminogen activator inhibitor $14 \mathrm{G} / 5 \mathrm{G}$ and $844 \mathrm{G} / \mathrm{A}$ variants in idiopathic recurrent pregnancy loss. American Journal of Reproductive Immunology 2013; 246-52.

4. Juhan-Vague I, Alessi MC. PAI-1, Obesity, insulin resistance and risk of cardiovascular events. Thromb Haemost 1997; 78: 656-60.

5. Attia J, Thakkinstian A, Wang Y, Lincz L, Parsons M, Sturm J, McGettigan P, Scott R, Meldrum C, Levi C. The PAI-1 4G/5G gene polymorphism and ischemic stroke: An association study and meta-analysis. J Stroke Cerebrovasc Dis 2007; 16: 173-9.

6. Su S, Chen S, Zhao J, Huang J, Wang X, Chen R, Gu D. Plasminogen activator inhibitor-1 gene selection of tagging single nucleotide polymorphisms and association with coronary heart disease.. Arteriosclerosis Thrombosis and Vascular Biology 2006; 26: 948-54.

7. 7.MargaglioneM, Cappucci G, Colaizzo D, Giuliani N Vecchione G, Grandone E, Pennelli O, Di Minno G. The PAI-1 Gene Locus 4G/5G Polymorphism Is Associated With a Family history of coronary artery disease. Arteriosclerosis, Thrombosis, and Vascular Biology 1998; 18: 152-6.

8. Abboud N, Ghazouani L, Saidi S, Ben-Hadj-Khalifa S, Addad F, Almawi WY, Mahjoub T. Association of PAI-1 4G/5G and -844G/A gene polymorphisms and changes in PAI-1 /tissue plasminogen activator levels in myocardial infarction: A case-control study. Genet Test Mol Biomarkers 2010; 14: 23-7.

9. Isogai C, Laug WE, Shimada H, Declerck PJ, Stins MF, Durden DL, Anat Erdreich-Epstein, and De Clerck Y.A. Plasminogen activator inhibitor-1 promotes angiogenesis by stimulating endothelial cell migration toward fibronectin. Cancer Res 2001; 61: 5587.

10. Soltanghoraee H, Memariani T, Aarabi M, Hantoushzadeh S, Arefi S. Association of ACE, PAI-1 and coagulation factor XIII gene polymorphisms with recurrent spontaneous abortion in Iranian patients. Journal of Reproduction and Infertility 2007; 7: 29.

11. Parveen F, Tuteja M, Agrawal S. Polymorphisms in MTHFR, MTHFD, and PAI1 and recurrent miscarriage among north Indian women. Arch. Gynecol. Obstet 2013; 288: 1171-7.

12. Carp H, Salomon O, Seidman D, Dardik R, Rosenberg N, Inbal A. Prevalence of genetic markers for thrombophilia in recurrent pregnancy loss. Human Reproduction 2002; 17: 1633-7.

13. Dossenbach-Glaninger A, Trotsenburg M, Dossenbach M, Oberkanins C, Moritz A, Krugluger W, Huber J, Hopmeier P. Plasminogen activator inhibitor 1 4G/5G polymorphism and coagulation factor XIII Val34Leu polymorphism impaired fibrinolysis and early pregnancy loss. Clinical Chemistry 2003; 49: 1081-6.

14. Wolf CE, Haubelt H, Pauer HU, Hinney B, Krome-Cesar C, Legler TJ, Hellstern P, Emons G, Zoll B, Köhler M. Recurrent pregnancy loss and its relation to FV Leiden, FII G20210A and polymorphisms of plasminogen activator and plasminogen activator inhibitor. Pathophysiol Haemost Thromb 2003; 33: 134-7.

15. Khaleghparast A, Morovvati S. Association between the PAI-1 4G/5G promoter polymorphism and recurrent miscarriage. Sci J Iran Blood Transfus Organ 2012; 9: $273-80$. 
16. Coulam CB, Jeyendran RS, Fishel LA, Roussev R. Multiple thrombophilic gene mutations rather than specific gene mutations are risk factors for recurrent miscarriage. American Journal of Reproductive Immunology 2006; 55: 360-8.

17. Reith A, Booth NA, Moore NR, Cruickshank DJ, Bennett B. Plasminogen activator inhibitors (PAI-1 and PAI-2) in normal pregnancies, pre-eclampsia and hydatidiform mole. Br J Obstet Gynaecol 1993; 100: 370-4.

18. Glueck CJ, Wang P, Fontaine RN, Sieve-Smith L, Tracy T, Moore SK. Plasminogen activator inhibitor activity: An independent risk factor for the high miscarriage rate during pregnancy in women with polycystic ovary syndrome. Metabolism 1999; 48: 1589-95.

19. Buchholz T, Lohse P, Rogenhofer N, Kosian E, Pihusch R, Thaler CJ. Polymorphisms in the ACE and PAI-1 genes are associated with recurrent spontaneous miscarriages. Hum. Reprod 2003; 18: 2473-7.

20. Farhad Khosravi, Saeed Zarei, Negah Ahmadvand, Zahra Akbarzadeh-Pasha et al. Association between plasminogen activator inhibitor 1 gene mutation and different subgroups of recurrent miscarriage and implantation failure. J Assist Reprod. Genet 2014; 31: 121-4.

21. Glueck CJ, Kupferminc MJ, Fontaine RN, Wang P, Weksler BB, Eldor A. Genetic hypofibrinolysis in complicated pregnancies. Obstetrics and Gynecology 2001; 97: 44-8. 